\title{
Genome-wide association study identifies five loci associated with lung function
}

Emmanouela Repapi ${ }^{1,64^{\star}}$, Ian Sayers ${ }^{2,64}$, Louise V Wain ${ }^{1,64}$, Paul R Burton ${ }^{1}$, Toby Johnson ${ }^{3}$, Ma'en Obeidat ${ }^{2}$, Jing Hua Zhao ${ }^{4}$, Adaikalavan Ramasamy ${ }^{5,6}$, Guangju Zhai ${ }^{7}$, Veronique Vitart ${ }^{8}$, Jennifer E Huffman ${ }^{8}$, Wilmar Igl $^{9}$, Eva Albrecht ${ }^{10}$, Panos Deloukas ${ }^{11}$, John Henderson ${ }^{12}$, Raquel Granell ${ }^{13}$, Wendy L McArdle ${ }^{14}$, Alicja R Rudnicka ${ }^{15}$, Wellcome Trust Case Control Consortium ${ }^{16}$, Inês Barroso ${ }^{11}$, Ruth J F Loos ${ }^{4}$, Nicholas J Wareham ${ }^{4}$, Linda Mustelin ${ }^{17}$, Taina Rantanen ${ }^{18}$, Ida Surakka ${ }^{19,20}$, Medea Imboden ${ }^{21}$, H Erich Wichmann $^{10,22,23}$, Ivica Grkovic $^{24}$, Stipan Jankovic ${ }^{24}$, Lina Zgaga ${ }^{25}$, Anna-Liisa Hartikainen ${ }^{26}$, Leena Peltonen ${ }^{11,19,20}$, Ulf Gyllensten ${ }^{9}$, Åsa Johansson ${ }^{9}$, Ghazal Zaboli ${ }^{9}$, Harry Campbell ${ }^{27}$, Sarah H Wild ${ }^{27}$, James F Wilson ${ }^{27}$, Sven Gläser ${ }^{28}$, Georg Homuth $^{29}$, Henry Völzke ${ }^{30}$, Massimo Mangino ${ }^{7}$, Nicole Soranzo ${ }^{7,11}$, Tim D Spector ${ }^{7}$, Ozren Polašek ${ }^{25,31}$, Igor Rudan ${ }^{24,27,31}$, Alan F Wright ${ }^{8}$, Markku Heliövaara ${ }^{20}$, Samuli Ripatti ${ }^{19,20}$, Anneli Pouta ${ }^{32}$,

Âsa Torinsson Naluai ${ }^{33}$, Anna-Carin Olin $^{34}$, Kjell Torén ${ }^{34}$, Matthew N Cooper ${ }^{35}$, Alan L James ${ }^{36,37}$, Lyle J Palmer ${ }^{35,37}$, Aroon D Hingorani ${ }^{38}$, S Goya Wannamethee ${ }^{39}$, Peter H Whincup ${ }^{15}$, George Davey Smith ${ }^{40}$, Shah Ebrahim ${ }^{41}$, Tricia M McKeever ${ }^{42,43}$, Ian D Pavord ${ }^{44}$, Andrew K MacLeod ${ }^{45}$, Andrew D Morris ${ }^{46}$, David J Porteous ${ }^{45}$, Cyrus Cooper ${ }^{47,48}$, Elaine Dennison ${ }^{47}$, Seif Shaheen ${ }^{5}$, Stefan Karrasch ${ }^{49}$, Eva Schnabel ${ }^{10}$, Holger Schulz ${ }^{49}$, Harald Grallert ${ }^{10}$, Nabila Bouatia-Naji ${ }^{50}$, Jérôme Delplanque ${ }^{50}$, Philippe Froguel ${ }^{50,51}$, John D Blakey ${ }^{2}$, The NSHD Respiratory Study Team ${ }^{6,52,53}$, John R Britton ${ }^{42,43}$, Richard W Morris ${ }^{39}$, John W Holloway ${ }^{54,55}$, Debbie A Lawlor ${ }^{40}$, Jennie Hui ${ }^{37,56}$, Fredrik Nyberg ${ }^{34,57}$, Marjo-Riitta Jarvelin ${ }^{6,32,58,59}$, Cathy Jackson $^{60}$, Mika Kähönen ${ }^{61}$, Jaakko Kaprio ${ }^{17,19,20}$, Nicole M Probst-Hensch ${ }^{21,62}$, Beate Koch ${ }^{28}$,

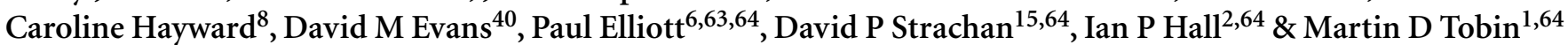

Pulmonary function measures are heritable traits that predict morbidity and mortality and define chronic obstructive pulmonary disease (COPD). We tested genome-wide association with forced expiratory volume in $1 \mathrm{~s}\left(\mathrm{FEV}_{1}\right)$ and the ratio of $\mathrm{FEV}_{1}$ to forced vital capacity (FVC) in the SpiroMeta consortium ( $n=20,288$ individuals of European ancestry). We conducted a meta-analysis of top signals with data from direct genotyping ( $n \leq 32,184$ additional individuals) and in silico summary association data from the CHARGE Consortium $(n=21,209)$ and the Health 2000 survey $(n \leq 883)$. We confirmed the reported locus at $4 q 31$ and identified associations with $\mathrm{FEV}_{1}$ or $\mathrm{FEV}_{1} / \mathrm{FVC}$ and common variants at five additional loci: $2 \mathrm{q} 35$ in $T N S 1\left(P=1.11 \times 10^{-12}\right), 4 \mathrm{q} 24$ in GSTCD $\left(2.18 \times 10^{-23}\right), 5 q 33$ in HTR4 $\left(P=4.29 \times 10^{-9}\right), 6 p 21$ in AGER $\left(P=3.07 \times 1^{-15}\right)$ and $15 q 23$ in THSD4 $\left(P=7.24 \times 10^{-15}\right)$. mRNA analyses showed expression of TNS1, GSTCD, AGER, HTR4 and THSD4 in human lung tissue. These associations offer mechanistic insight into pulmonary function regulation and indicate potential targets for interventions to alleviate respiratory disease.

Measures of pulmonary function, such as $\mathrm{FEV}_{1}$ and $\mathrm{FEV}_{1} / \mathrm{FVC}$ ratio, are important predictors of population morbidity and mortality ${ }^{1-4}$ as well as forming the basis for the diagnosis of COPD. It is well established that pulmonary function is partially genetically determined. Twin studies in European and US populations give heritability estimates for $\mathrm{FEV}_{1}$ as high as 0.77 (refs. 5,6). Longitudinal studies in families suggest that genetic effects are consistent over time ${ }^{7}$. Genetic determinants of pulmonary function seem to operate, at least in part, independent of disease status (such as asthma) and smoking status ${ }^{8}$, suggesting that population-based association studies are a viable way to identify key genetic determinants of lung function.

Adequately powered genome-wide association studies (GWAS) using hundreds of thousands of common SNPs can identify loci associated with common diseases and the quantitative traits that underlie them. Collaborative studies achieving sample sizes in excess of 10,000 have been able to identify associations with common genetic variants with typically modest effect sizes (usually $<0.1$ s.d.) ${ }^{9}$. In the past

*A full list of author affiliations appears at the end of the paper. 
year, GWAS have reported association between an intergenic locus at chromosome $4 \mathrm{q} 31$ and $\mathrm{FEV}_{1} / \mathrm{FVC}$ ratio and COPD, but no large-scale collaborative GWAS have yet been undertaken for lung function ${ }^{10,11}$.

If common SNPs underlying lung function have modest effects, very large sample sizes will be required to identify them. We therefore established the SpiroMeta consortium to facilitate large-scale metaanalysis of GWAS of lung function. Here we report a meta-analysis of GWAS in the SpiroMeta consortium, comprising 20,288 individuals of European ancestry, that tested association between cross-sectional lung function measures and $\sim 2.5$ million genotyped or imputed SNPs (stage 1). We followed up SNPs drawn from the most significantly associated loci in up to 32,184 individuals by direct genotyping (stage 2a) and using in silico summary association data relating to a further 22,092 individuals (stage 2b). These studies confirm the previous reported association at $4 \mathrm{q} 31$ and show that five previously unreported loci are robustly associated with lung function.

\section{RESULTS}

\section{Genome-wide association with lung function (stage 1)}

We included 14 studies of individuals of European ancestry, with sample sizes totaling 20,288 (Table 1). All individuals had measures of $\mathrm{FEV}_{1}$ and FVC and smoking status recorded. $\mathrm{FEV}_{1}$ and (separately) $\mathrm{FEV}_{1} / \mathrm{FVC}$ measures were adjusted for age, age ${ }^{2}$, sex, height and ancestry principal components within each study. Genome-wide genotyping was

Table 1 Study characteristics

\begin{tabular}{|c|c|c|c|c|c|c|c|c|c|c|}
\hline Study & $\begin{array}{c}N \\
\text { total }\end{array}$ & $\begin{array}{c}N \\
\text { male }\end{array}$ & $\begin{array}{c}N \\
\text { female }\end{array}$ & $\begin{array}{l}\text { Age range }(\mathrm{y}) \\
\text { at } \mathrm{FEV}_{1} / \mathrm{FVC} \\
\text { measurement }\end{array}$ & $\begin{array}{c}\text { Mean age, } \\
\text { y (s.d.) }\end{array}$ & $\begin{array}{c}\text { Mean } \mathrm{FEV}_{1} \text {, } \\
\quad \text { I (s.d.) }\end{array}$ & $\begin{array}{c}\text { Mean FVC, } \\
\text { I (s.d.) }\end{array}$ & $\begin{array}{c}\text { Mean } \\
\mathrm{FEV}_{1} / \mathrm{FVC} \\
\text { (s.d.) }\end{array}$ & $\begin{array}{c}N \\
\text { never- } \\
\text { smokers }\end{array}$ & $\begin{array}{c}N \\
\text { ever- } \\
\text { smokers }\end{array}$ \\
\hline \multicolumn{11}{|l|}{ Stage 1: GWAS } \\
\hline B58C T1DGC & 2,343 & 1,131 & 1,212 & $44-45$ & 44.5 & $3.31(0.78)$ & $4.19(0.96)$ & $0.79(0.08)$ & 692 & 1,651 \\
\hline B58C WTCCC & 1,372 & 691 & 681 & $44-45$ & 44.5 & $2.93(0.75)$ & $4.18(0.96)$ & $0.79(0.08)$ & 394 & 978 \\
\hline EPIC obese cases & 1,104 & 476 & 628 & $39-76$ & $59.1 \quad(8.8)$ & $2.35(0.69)$ & $2.84(0.87)$ & $0.82(0.17)$ & 489 & 615 \\
\hline FTC & 134 & 13 & 121 & $23-76$ & $57.4(19.3)$ & $2.69(0.94)$ & $2.93(0.61)$ & $0.79(0.09)$ & 104 & 30 \\
\hline KORA S3 & 555 & 261 & 294 & $29-73$ & $47.6 \quad(9.0)$ & $3.43(0.78)$ & $4.18(0.99)$ & $0.83(0.07)$ & 266 & 289 \\
\hline Korcula & 825 & 300 & 525 & $18-90$ & $55.5(13.5)$ & $2.84(0.81)$ & $3.37(0.93)$ & $0.84(0.09)$ & 397 & 428 \\
\hline NFBC1966 & 4,556 & 2,182 & 2,374 & $31-31$ & $31.0 \quad(0)$ & $3.96(0.79)$ & $4.73(0.99)$ & $0.84(0.06)$ & 1,648 & 2,908 \\
\hline NSPHS & 549 & 255 & 294 & $18-91$ & $50.0(19.1)$ & $3.02(0.95)$ & $3.68(1.12)$ & $0.82(0.09)$ & 464 & 85 \\
\hline ORCADES & 692 & 322 & 370 & $19-93$ & $54.9(15.3)$ & $2.88(0.84)$ & $3.58(0.98)$ & $0.80(0.09)$ & 404 & 288 \\
\hline
\end{tabular}

Stage 1 sample size $\quad 20,288$

Stage 2a: studies with direct genotyping

\begin{tabular}{|c|c|c|c|c|c|c|c|c|c|c|}
\hline ADONIX & 1,338 & 635 & 703 & $25-75$ & $49.2(13.6)$ & $3.35(0.86)$ & $4.24(1.02)$ & $0.79(0.07)$ & 743 & 595 \\
\hline BHS & 4,350 & 1,793 & 2,557 & $18-96$ & $50.1(17.0)$ & $3.02(0.97)$ & $3.89(1.16)$ & $0.77(0.08)$ & 2,459 & 1,891 \\
\hline BRHS & 3,897 & 3,897 & 0 & $60-79$ & $68.7 \quad(5.5)$ & $2.57(0.69)$ & $3.37(0.84)$ & $0.77(0.11)$ & 1,132 & 2,765 \\
\hline BWHHS & 3,644 & 0 & 3,644 & $59-80$ & $68.8 \quad(5.5)$ & $1.98(0.52)$ & $2.82(0.76)$ & $0.71(0.09)$ & 2,060 & 1,584 \\
\hline Gedling & 1,263 & 632 & 631 & $27-80$ & $56.2(12.3)$ & $2.85(0.85)$ & $3.68(1.02)$ & $0.77(0.07)$ & 633 & 630 \\
\hline GS:SFHS & 5,474 & 2,254 & 3,220 & $18-89$ & $46.0(14.3)$ & $3.15(0.87)$ & $4.11(1.03)$ & $0.77(0.10)$ & 3,005 & 2,469 \\
\hline $\mathrm{HCS}$ & 2,850 & 1,511 & 1,339 & $59-73$ & $66.1 \quad(2.8)$ & $2.44(0.68)$ & $3.42(0.92)$ & $0.72(0.09)$ & 1,319 & 1,531 \\
\hline KORA F4 & 1,305 & 610 & 695 & $41-61$ & $51.6 \quad(5.7)$ & $3.32(0.81)$ & $4.28(1.00)$ & $0.78(0.06)$ & 499 & 806 \\
\hline NFBC1986 & 4,946 & 2,379 & 2,567 & $15-17$ & $16.0 \quad(0.38)$ & $3.77(0.70)$ & $4.30(0.84)$ & $0.88(0.08)$ & 3,708 & 1,238 \\
\hline Nottingham Smokers & 509 & 280 & 229 & $40-89$ & $59.5(10.4)$ & $2.00(0.95)$ & $3.01(1.06)$ & $0.64(0.16)$ & 0 & 509 \\
\hline NSHD & 2,608 & 1,308 & 1,300 & $53-53$ & (0) & $2.80(0.70)$ & $3.50(0.89)$ & $0.81(0.19)$ & 1,080 & 1,528 \\
\hline
\end{tabular}

Stage 2a sample size $\quad 32,184$

\section{Stage 2b: studies with in silico data}

Health $2000 \quad 883$

CHARGE $^{\text {a }}$ (ref. 30) $\quad 21,209$

Stage 2b sample size $\quad 22,092$

$427 \quad 456 \quad 30-75$
$50.2(11.0) \quad 3.32(0.91)$
$4.19(1.08)$

$0.79(0.07)$

266

617

Characteristics are shown for studies analyzed in stage 1 (GWAS meta-analysis), stage 2a (direct genotyping follow-up, 10 SNPs) and stage 2b (in silico follow-up, 30 SNPs). Stage 1 studies: ALSPAC, Avon Longitudinal Study of Parents and Children; B58C-T1DGC, British 1958 Birth Cohort-Type 1 Diabetes Genetics Consortium; B58C-WTCCC, British 1958 Birth Cohort-Wellcome Trust Case Control Consortium; EPIC obese cases, European Prospective Investigation into Cancer and Nutrition, Obese Cases; EPIC population based, European Prospective Investigation into Cancer and Nutrition Cohort; FTC, Finnish Twin Cohort incorporating FinnTwin16 and FITSA; KORA S3, Cooperative Health Research in the Region of Augsburg; the Korcula study; NFBC1966, Northern Finland Birth Cohort of 1966; NSPHS, Northern Sweden Population Health Study; ORCADES, Orkney Complex Disease Study; SHIP, Study of Health in Pomerania; the TwinsUK study; the Vis study. Stage 2a studies: ADONIX, Adult-Onset Asthma and Nitric Oxide; BHS, Busselton Health Study; BRHS, British Regional Heart Study; BWHHS, British Women's Heart and Health Study; the Gedling study; GS:SFHS, Generation Scotland: Scottish Family Health Study; HCS, Hertfordshire Cohort Study; KORA F4, Cooperative Health Research in the Region of Augsburg; NFBC1986, Northern Finland Birth Cohort of 1986; the Nottingham Smokers study; NSHD, Medical Research Council National Survey of Health and Development (also known as the British 1946 Birth Cohort). Stage 2b studies: Health 2000, Finnish Health 2000 survey; CHARGE, Cohorts for Heart and Aging Research in Genomic Epidemiology.

${ }^{a}$ Characteristics of the constituent studies of the CHARGE Consortium are presented in the companion paper from the CHARGE Consortium ${ }^{30}$. 
a

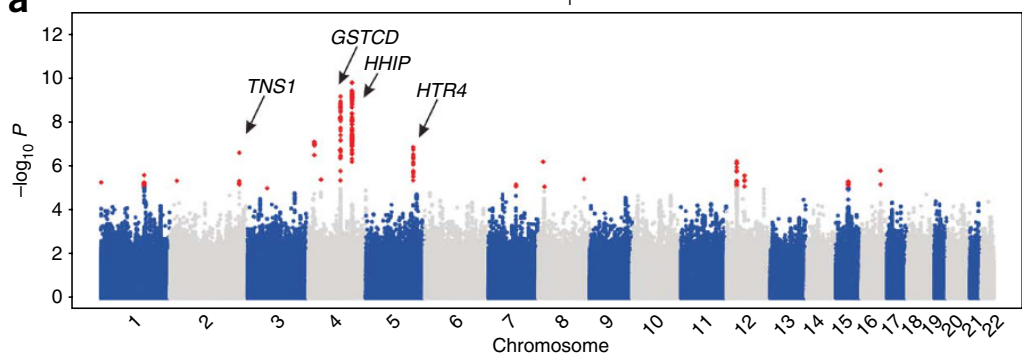

b

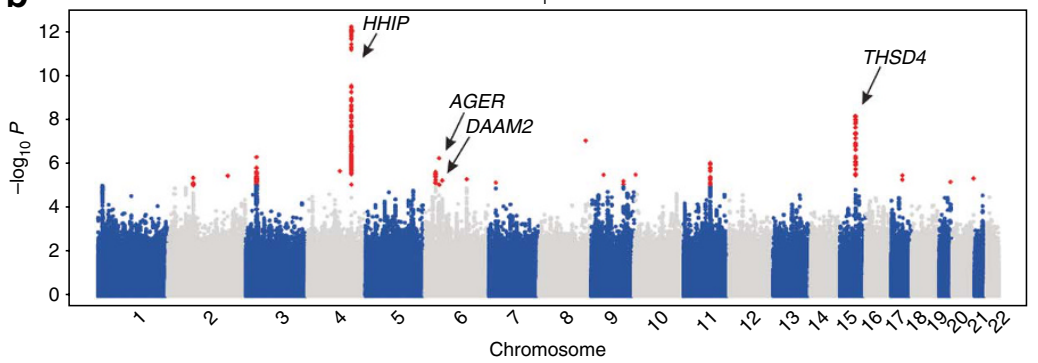

Figure 1 Manhattan plots of association results for $\mathrm{FEV}_{1}$ and $\mathrm{FEV}_{1} / \mathrm{FVC}$ (analysis stage 1 ).

$(\mathbf{a}, \mathbf{b})$ Manhattan plots ordered by chromosome position. SNPs for which $-\log _{10} P>5$ are indicated in red. The six loci indicated by arrows showed association with $\mathrm{FEV}_{1}$ (a) or $\mathrm{FEV}_{1} / \mathrm{FVC}$ (b; $P<5 \times 10^{-8}$ ) in the meta-analysis of data from stages $1,2 \mathrm{a}$ and $2 \mathrm{~b}$.

and meta-analysis levels to avoid overinflation of test statistics owing to population structure or relatedness. Test statistic inflation before applying genomic control at the meta-analysis level was modest $\left(\lambda_{\mathrm{GC}}=1.046\right.$ for $\mathrm{FEV}_{1}$ and 1.035 for $\mathrm{FEV}_{1} / \mathrm{FVC}$ ). The plots of meta-analysis test statistics against expected values under the null hypothesis showed an excess of extreme values even after exclusion of the previously reported $^{11} 4 \mathrm{q} 31$ locus near HHIP, indicative of additional loci associated with lung function (Supplementary Fig. 1a,b).

We observed independent regions of assoundertaken with a variety of platforms, and standard quality control measures were used (Online Methods and Supplementary Table 1). Genotypes were imputed for 2.5 million autosomal SNPs from HapMap CEU data and tested for association separately for the inverse-normal transformed residuals of $\mathrm{FEV}_{1}$ and $\mathrm{FEV}_{1} / \mathrm{FVC}$ under an additive genetic model. We carried out meta-analysis of study-specific test statistics using an inverse variance weighting. We applied genomic control at the study ciation at 17 loci with $P<1 \times 10^{-5}$ for $\mathrm{FEV}_{1}$ and 23 for $\mathrm{FEV}_{1} / \mathrm{FVC}$ (Figs. 1a,b and 2), including three regions (4q24 in GSTCD, $4 \mathrm{q} 31$ near HHIP and $15 \mathrm{q} 23$ in THSD4) that reached $P<5 \times 10^{-8}$ in the stage 1 GWAS data alone, corresponding to a threshold of $P<0.05$ after adjusting for 1 million independent tests ${ }^{12}$. SNP rs12504628, which was associated with both $\mathrm{FEV}_{1} / \mathrm{FVC}\left(P=6.48 \times 10^{-13}\right.$; Fig. 2c and Table 2$)$ and $\operatorname{FEV}_{1}\left(P=1.50 \times 10^{-10}\right.$; Table 3$)$, lies in an
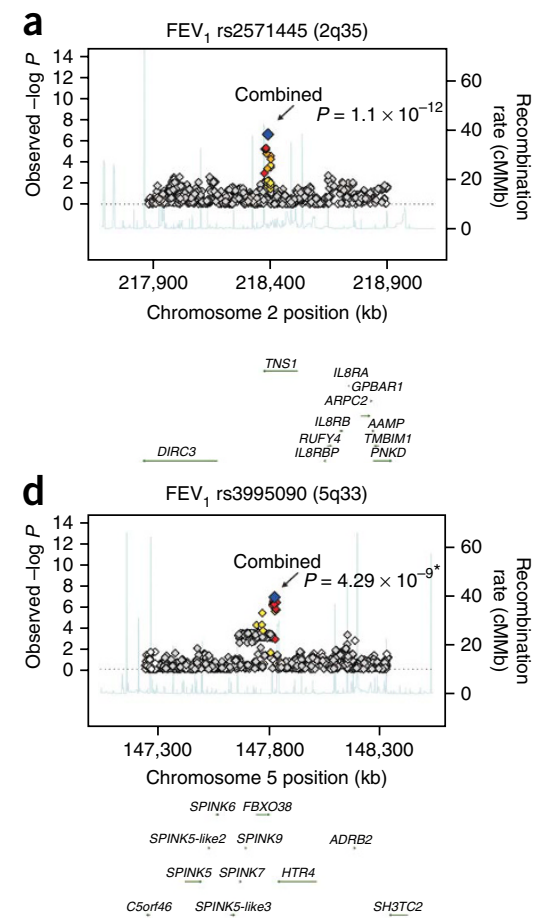

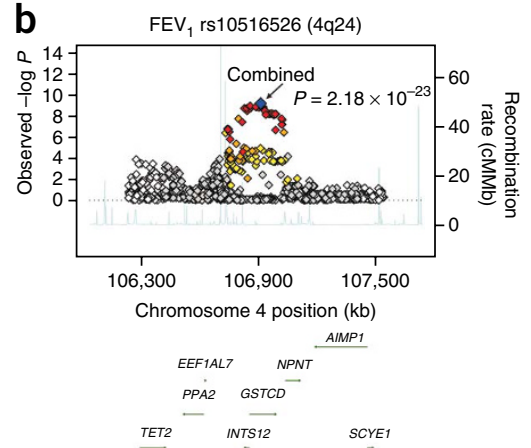

\section{e}

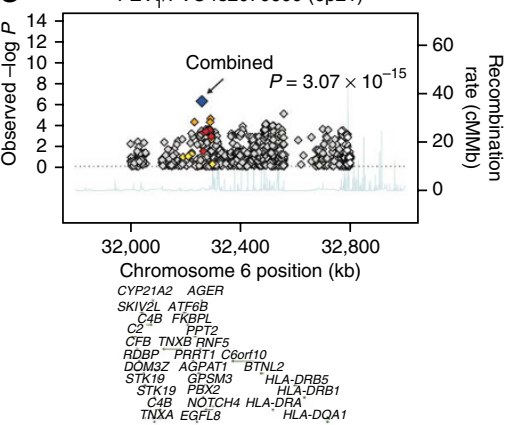

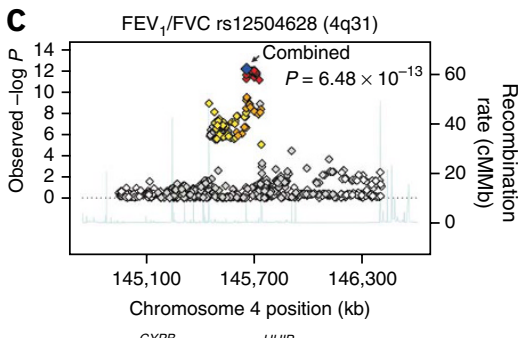

GYPB HHIP

ABCE1

GYPE GYPA

ANAPC10

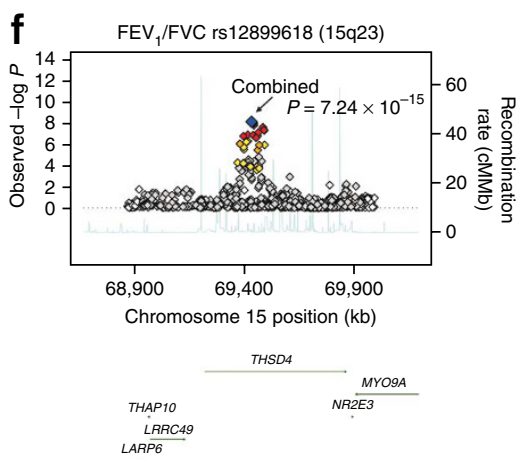

$\diamond$ Top SNP $\diamond r^{2}>0.8 \diamond r^{2}>0.5 \diamond r^{2}>0.2 \diamond r^{2}<0.2 \diamond r^{2}$ unknown

Figure 2 Regional association plots of six lung function-associated loci. (a-f) Statistical significance of each SNP on the -log 10 Scale as a function of chromosome position (NCBI build 36) in the meta-analysis of stage 1 data alone. The sentinel SNP at each locus is shown in blue; the correlations $\left(r^{2}\right)$ of each of the surrounding SNPs to the sentinel SNP are shown in the indicated colors. The six loci included are those that showed association with $\mathrm{FEV}_{1}$ or $\mathrm{FEV}_{1} / \mathrm{FVC}\left(P<5 \times 10^{-8}\right)$ in the meta-analysis of data from stages $1,2 \mathrm{a}$ and $2 \mathrm{~b}$. The combined $P$ values for all stages are indicated by arrows. The relevant trait ( $\mathrm{FEV}_{1}$ or $\mathrm{FEV}_{1} / \mathrm{FVC}$ ratio) is indicated for each plot. For $\mathrm{rs} 12504628$, the plot shows only the association of $\mathrm{FEV} / \mathrm{FVC}$; this SNP was associated $\left(P<5 \times 10^{-8}\right)$ with both $\mathrm{FEV}_{1}$ and $\mathrm{FEV}_{1} / \mathrm{FVC}$. Fine-scale recombination rate is plotted in blue ${ }^{39}$. Combined $P$ value from stages 1 and 2 a only; SNP rs3995090 had low imputation quality in the CHARGE Consortium data and so was not included in stage 2 b. 
Table 2 Loci associated with lung function

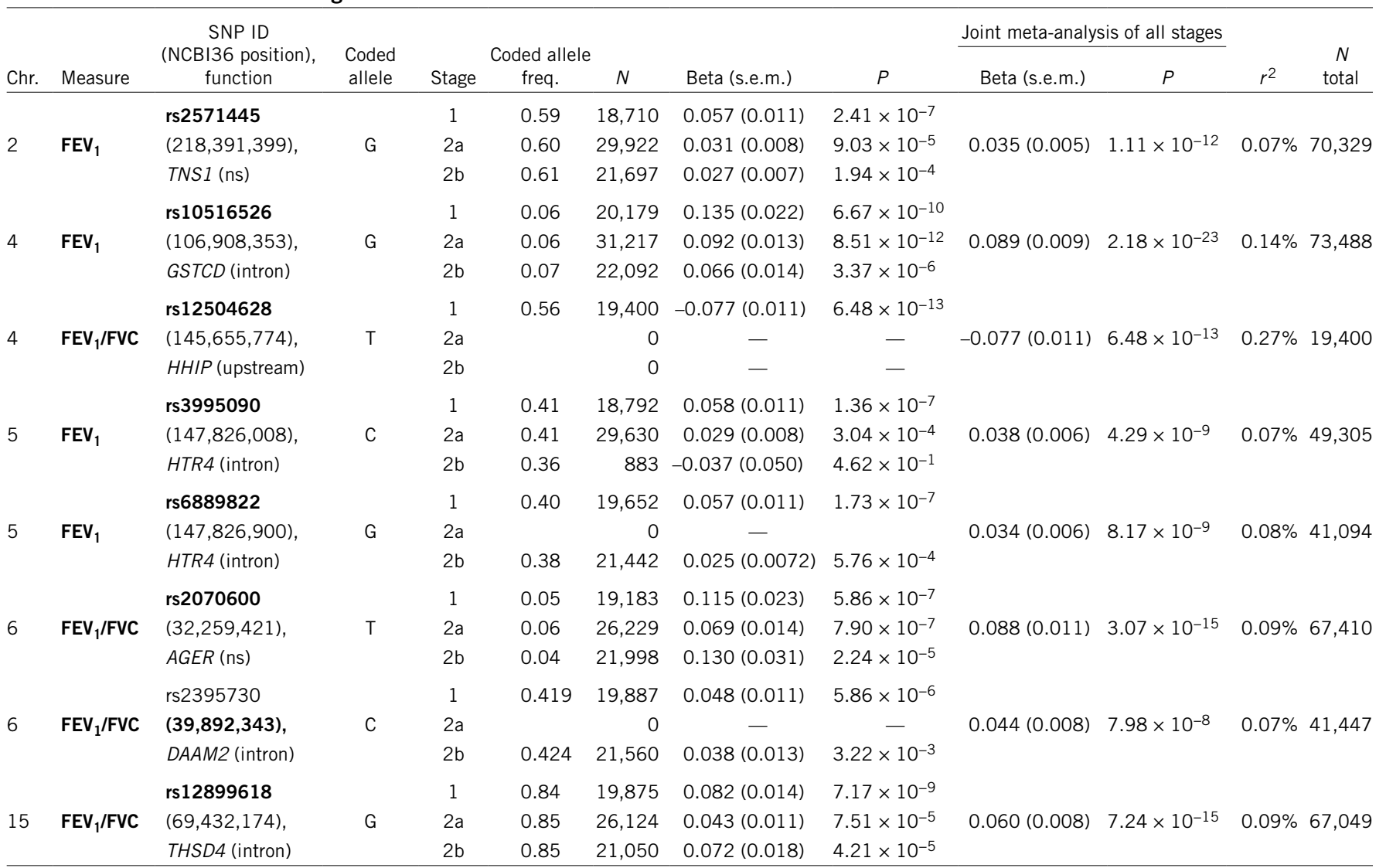

Shown are the top SNPs or SNPs for each independent locus associated $\left(P<5 \times 10^{-7}\right)$ with FEV or FEV $_{1} / \mathrm{FVC}_{\text {in }}$ a joint analysis of up to 74,564 individuals of European ancestry from the SpiroMeta GWAS (stage 1), follow-up genotyping (stage 2a) and in silico data from the CHARGE Consortium (companion paper in this issue ${ }^{30}$ ) and the Health 2000 study (stage $2 \mathrm{~b}$ ). The six genome-wide significant $\left(P<5 \times 10^{-8}\right)$ loci are indicated in bold. Results are also shown for rs2395730 (DAAM2), as this locus fell just below genomewide significance after meta-analysis of stage 1 and $2 \mathrm{~b}$ data (it was not selected for stage 2 a genotyped follow-up). For the GWAS (stage 1 and $2 \mathrm{~b}$ ) data, the sample sizes ( $N$ ) shown are the effective sample sizes. Effective sample size within each study is the product of sample size and imputation quality metric. Total sample size is the sum of the $N$ effective values across all stage 1 and $2 \mathrm{~b}$ studies, plus the sample size from the directly genotyped (stage 2a) studies; for each SNP, this is lower than 74,564 individuals owing to missing genotypes and imperfect imputation. Joint meta-analysis includes data from stages $1,2 \mathrm{a}$ and $2 \mathrm{~b}$. Beta values reflect effect-size estimates on an inverse-normal transto missing genotypes and imperfect imputation. Joint meta-analysis includes data from stages $1,2 \mathrm{a}$ and $2 \mathrm{~b}$. Beta values reflect effect-size estimates on an inverse-normal transformed scale after adjustments for age, age ${ }^{2}$, sex, height and ancestry principal components. SNP rs 12504628 showed association with both $\mathrm{FEV}{ }_{1}$ and $\mathrm{FEV} / \mathrm{FVC}_{1}(P<5 \times 10-8)$
statistics for the strongest association ( $\left.\mathrm{FEV}_{1} / \mathrm{FVC}\right)$ are shown. As this association has been previously published ${ }^{11}$, rs 12504628 was not assessed in the follow-up studies, so statistics are not presented for stages $2 a$ and $2 b$ for rs 12504628 . SNP rs 3995090 was genotyped in stage $2 a$ follow-up studies and was available in Health 2000 study data, but owing to low imputation quality for rs3995090 in the CHARGE Consortium data, an alternative SNP in the region, rs6889822, was selected for in silico exchange with the CHARGE Consortium. The estimated proportion of variance explained by each SNP in the joint meta-analysis is shown $\left(r^{2}\right)$. ns, nonsynonymous coding SNP.

intergenic region upstream of HHIP and spanning $\sim 300 \mathrm{~kb}$ at $4 \mathrm{q} 31$ that has been associated with lung function ${ }^{11}, \mathrm{COPD}^{11}$ and height ${ }^{9}$. Our top SNP rs12504628 was in strong linkage disequilibrium (LD; $\left.r^{2}=0.97\right)$ with the previously reported SNP associated with lung function, $\operatorname{rs} 13147758\left(P=5.30 \times 10^{-10}\right.$ for $\mathrm{FEV}_{1}$ and $P=1.11 \times 10^{-12}$ for $\mathrm{FEV}_{1} / \mathrm{FVC}$ in our data), and with SNPs associated previously with

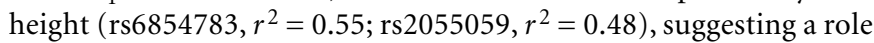
in skeletal growth and development. The hedgehog gene family, of which HHIP is a member, encodes signaling molecules involved in regulating lung morphogenesis, suggesting other mechanisms underlying these associations ${ }^{13}$. This intergenic region also contains multiple ESTs in human fetal lung (UCSC Browser).

\section{Follow-up analyses (stage 2)}

To validate potential associations with lung function, we selected 10 SNPs for further genotyping in additional studies of European ancestry (stage 2a, 32,184 individuals; Supplementary Table 2) and 30 SNPs for in silico follow-up (stage 2b; Supplementary Table 3). We obtained the in silico association results from the Health 2000 study (883 individuals) and from the CHARGE Consortium (21,209 individuals). Metaanalysis of the association results across stages $1,2 \mathrm{a}$ and $2 \mathrm{~b}$ showed five novel loci reaching genome-wide significance $\left(P<5 \times 10^{-8}\right)$ : $2 \mathrm{q} 35$ in TNS1, 4q24 in GSTCD, 5q33 in HTR4, 6p21 in AGER and 15q23 in THSD4 (Table 2 and Fig. 2). A further locus, 6p21 in DAAM2, which was not selected for further genotyping follow-up in stage $2 a$, fell just below the threshold for genome-wide significance for association with $\mathrm{FEV}_{1} / \mathrm{FVC}$ after meta-analysis across stages 1 and $2 \mathrm{~b}$ (rs2395730, $P=7.98 \times 10^{-8}$; Supplementary Table 3 and Table 2 ).

The strongest association of $\mathrm{FEV}_{1}$ was at $4 \mathrm{q} 24$ in GSTCD (rs10516526, $P=2.18 \times 10^{-23}$; Table 2 and Fig. 2b). Relatively little is known about GSTCD, but the presence of the C-terminal $\alpha$-helical domain common to the glutathione $S$-transferase (GST) family of enzymes suggests this protein is involved in cellular detoxification by catalyzing conjugation of glutathione to products of oxidative stress ${ }^{14}$. GST enzymes also show glutathione peroxidase activity regulating the synthesis of prostaglandins and leukotrienes ${ }^{14}$. To explore the potential function of GSTCD, we conducted a protein homology search and identified homology with chloride intracellular channels $1,3,4,5$ and 6 , suggesting a role for GSTCD beyond the GST enzyme family. Genes in the region also include INTS12 and NPNT. INTS12 associates with RNA polymerase II and mediates $3^{\prime}$-end processing of small nuclear RNA ${ }^{15}$. 
Table 3 Relation of SNPs at genome-wide significant loci to $\mathrm{FEV}_{1}, \mathrm{FVC}$ and $\mathrm{FEV}_{1} / \mathrm{FVC}$, and impact of adjustment for smoking in stage 1 (SpiroMeta GWAS) data

\begin{tabular}{|c|c|c|c|c|c|c|c|c|c|c|c|}
\hline \multirow{2}{*}{$\begin{array}{l}\text { SNP ID (NCBI36 } \\
\text { position), function }\end{array}$} & \multirow[b]{2}{*}{ Chr. } & \multirow{2}{*}{$\begin{array}{l}\text { Coded } \\
\text { allele }\end{array}$} & \multirow{2}{*}{$\begin{array}{l}\text { Noncoded } \\
\text { allele }\end{array}$} & \multirow[b]{2}{*}{$N$} & \multirow[b]{2}{*}{ Measure } & \multicolumn{3}{|c|}{ Unadjusted stage 1 analyses } & \multicolumn{3}{|c|}{ Smoking-adjusted stage 1 analyses } \\
\hline & & & & & & Beta & s.e.m. & $P$ & Beta & s.e.m. & $P$ \\
\hline rs2571445 & 2 & G & A & 18,710 & $\mathrm{FEV}_{1}$ & 0.057 & 0.011 & $2.41 \times 10^{-7}$ & 0.055 & 0.012 & $2.12 \times 10^{-6}$ \\
\hline (218391399), & & & & & FVC & 0.041 & 0.011 & $1.84 \times 10^{-4}$ & 0.038 & 0.011 & $8.94 \times 10^{-4}$ \\
\hline TNS1 (ns) & & & & & $\mathrm{FEV}_{1} / \mathrm{FVC}$ & 0.026 & 0.011 & 0.018 & 0.031 & 0.012 & 0.0073 \\
\hline rs10516526 & 4 & G & $A$ & 20,179 & $\mathrm{FEV}_{1}$ & 0.135 & 0.022 & $6.67 \times 10^{-10}$ & 0.138 & 0.023 & $2.06 \times 10^{-9}$ \\
\hline (106908353), & & & & & FVC & 0.112 & 0.022 & $2.53 \times 10^{-7}$ & 0.119 & 0.023 & $1.29 \times 10^{-7}$ \\
\hline GSTCD (intron) & & & & & $\mathrm{FEV}_{1} / \mathrm{FVC}$ & 0.038 & 0.022 & 0.084 & 0.030 & 0.023 & 0.19 \\
\hline rs12504628 & 4 & $\mathrm{~T}$ & C & 19,400 & $\mathrm{FEV}_{1}$ & -0.068 & 0.011 & $1.50 \times 10^{-10}$ & -0.069 & 0.011 & $7.18 \times 10^{-10}$ \\
\hline (145655774), & & & & & FVC & -0.021 & 0.011 & 0.046 & -0.020 & 0.011 & 0.066 \\
\hline HHIP (upstream) & & & & & $\mathrm{FEV}_{1} / \mathrm{FVC}$ & -0.077 & 0.011 & $6.48 \times 10^{-13}$ & -0.080 & 0.011 & $8.25 \times 10^{-13}$ \\
\hline rs3995090 & 5 & $\mathrm{C}$ & $A$ & 18,792 & $\mathrm{FEV}_{1}$ & 0.058 & 0.011 & $1.36 \times 10^{-7}$ & 0.059 & 0.011 & $1.47 \times 10^{-7}$ \\
\hline (147826008), & & & & & FVC & 0.023 & 0.011 & 0.034 & 0.031 & 0.011 & 0.0048 \\
\hline HTR4 (intron) & & & & & $\mathrm{FEV}_{1} / \mathrm{FVC}$ & 0.045 & 0.011 & $1.92 \times 10^{-5}$ & 0.038 & 0.011 & $7.0 \times 10^{-4}$ \\
\hline rs6889822 & 5 & G & $A$ & 19,652 & $\mathrm{FEV}_{1}$ & 0.057 & 0.011 & $1.73 \times 10^{-7}$ & 0.062 & 0.011 & $5.23 \times 10^{-8}$ \\
\hline (147826900), & & & & & FVC & 0.025 & 0.011 & 0.021 & 0.034 & 0.011 & 0.0025 \\
\hline HTR4 (intron) & & & & & $\mathrm{FEV}_{1} / \mathrm{FVC}$ & 0.046 & 0.011 & $2.15 \times 10^{-5}$ & 0.038 & 0.011 & $7.3 \times 10^{-4}$ \\
\hline rs2070600 & 6 & $\mathrm{~T}$ & C & 19,183 & $\mathrm{FEV}_{1}$ & 0.027 & 0.023 & 0.24 & 0.044 & 0.024 & 0.072 \\
\hline (32259421), & & & & & FVC & -0.043 & 0.023 & 0.063 & -0.035 & 0.024 & 0.14 \\
\hline$A G E R(\mathrm{~ns})$ & & & & & $\mathrm{FEV}_{1} / \mathrm{FVC}$ & 0.115 & 0.023 & $5.86 \times 10^{-7}$ & 0.126 & 0.024 & $2.42 \times 10^{-7}$ \\
\hline rs12899618 & 15 & $\mathrm{G}$ & $A$ & 19,875 & $\mathrm{FEV}_{1}$ & 0.028 & 0.014 & 0.047 & 0.033 & 0.015 & 0.025 \\
\hline (69432174), & & & & & FVC & -0.024 & 0.014 & 0.085 & -0.024 & 0.015 & 0.11 \\
\hline THSD4 (intron) & & & & & $\mathrm{FEV}_{1} / \mathrm{FVC}$ & 0.082 & 0.014 & $7.17 \times 10^{-9}$ & 0.092 & 0.015 & $6.56 \times 10^{-10}$ \\
\hline
\end{tabular}

Each SNP included in table showed genome-wide significant association $\left(P<5 \times 10^{-8}\right)$ with either $\mathrm{FEV}_{1}$ or FEV $/$ FVC in data from stages 1 , $2 \mathrm{a}$ and $2 \mathrm{~b}$. Beta values shown reflect effect-size estimates on an inverse-normal transformed scale in the stage 1 data. Effective sample size was calculated within each study as the product of sample size and imputation quality metric and were summed across studies to calculate total effective sample size $(N)$. Estimates from analyses unadjusted for smoking status and adjusted for imputation quality metric and were summed across st

The second locus associated with $\mathrm{FEV}_{1}$ was at $2 \mathrm{q} 35$, localized to the TNS1 gene (nonsynonymous coding SNP rs2571445, $P=1.11 \times 10^{-12}$; Table 2 and Fig. $2 a)$. The protein this encodes, tensin-1, is an actinbinding protein that contains Src homology 2 domains, suggesting a role in linking cytoskeletal changes with signal transduction ${ }^{16}$. Tensin-1 may be functionally involved in cell migration ${ }^{17}$.

Multiple genes potentially underlie the third locus associated with $\mathrm{FEV}_{1}$ at $5 \mathrm{q} 33$. The most strongly associated SNPs in this region, rs3995090 and rs6889822 $\left(P=4.29 \times 10^{-9}\right.$ and $P=8.17 \times 10^{-9}$; Table 2 and Fig. 2d), are located in an intron in HTR4 and are part of a cluster of associated SNPs also spanning a SPINK5-like gene, SPINK7, SPINK9 and FBXO38. HTR4, which encodes 5-hydroxytryptamine receptor-4, is expressed in neurons in the respiratory pre-Bötzinger complex. Activation of this $\mathrm{G}$ protein-coupled receptor protects spontaneous respiratory activity ${ }^{18}$. Notably, selective antagonism of HTR4 in human bronchial strips in vitro attenuates the facilitation of electric field-stimulated cholinergic contraction by 5-hydroxytryptamine, suggesting a role for HTR4 in mediating airway caliber ${ }^{19}$. HTR4 expression has recently been confirmed in airway epithelial type II cells, where receptor stimulation seems to regulate cytokine responses ${ }^{20}$. The SPINK family of serine protease inhibitors may have a role in antimicrobial protection of mucous epithelia ${ }^{21}$. F-box protein-38 (encoded by FBXO38) is a member of a family of proteins that are believed to mediate protein-protein interactions and protein degradation $^{22}$.

The strongest association with $\mathrm{FEV}_{1} / \mathrm{FVC}$ was at $6 \mathrm{p} 21$, a generich region of the major histocompatibility complex (MHC). The extended LD in this region of the MHC prevented accurate localization of the association signal. However, we observed the peak of association for a nonsynonymous coding SNP in AGER ( $r$ s2070600, $P=3.07 \times 10^{-15}$; Table 2 and Fig. $2 \mathbf{e}$ ), which is a plausible candidate for causal association. AGER, also known as RAGE, is a multiligand receptor of the immunoglobulin superfamily ${ }^{23}$. AGER is highly expressed in the lung, in particular alveolar epithelial cells ${ }^{24}$, with a potential role in epithelium-extracellular matrix interactions. Reduced AGER expression has been identified in individuals with idiopathic pulmonary fibrosis ${ }^{25}$, and Ager $^{-/}$mice develop agerelated pulmonary fibrosis ${ }^{26}$. Another candidate in this region is the nearby gene NOTCH4, a member of the family of transmembrane receptors involved in cell fate decisions ${ }^{27}$. Notch 4 is expressed in endothelial cells of the adult mouse lung, where it is believed to regulate angiogenesis ${ }^{28}$.

The second identified association with $\mathrm{FEV}_{1} / \mathrm{FVC}$ was at $15 \mathrm{q} 23$, encompassing the THSD4 gene ( $r$ 12899618, $P=7.24 \times 10^{-15}$; Table 2 and Fig. 2f). THSD4 shows homology with members of the thrombospondin family of extracellular calcium-binding proteins that modulate cellular attachment, proliferation and migration and have been implicated in wound healing, inflammation and angiogenesis ${ }^{29}$.

For each of the loci we reported, the estimated effect sizes were broadly consistent across the GWAS (Fig. 3).

\section{Association of variants with FVC}

We tested the top SNP at each of the loci showing genome-wide significant association $\left(P<5 \times 10^{-8}\right)$ with $\mathrm{FEV}_{1}$ or $\mathrm{FEV}_{1} / \mathrm{FVC}$ for association with the other of the two traits, and with FVC in the stage 1 studies (Table 3 ). In addition to being associated with $\mathrm{FEV}_{1}$, rs10516526 in GSTCD was associated with FVC $\left(P=2.53 \times 10^{-7}\right)$ but showed no discernible effect on $\mathrm{FEV}_{1} / \mathrm{FVC}$. 


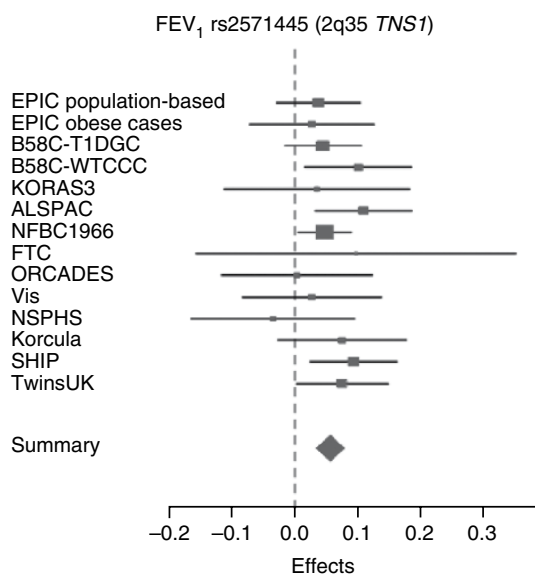

FEV $_{1}$ rs3995090 (5q33 HTR4)

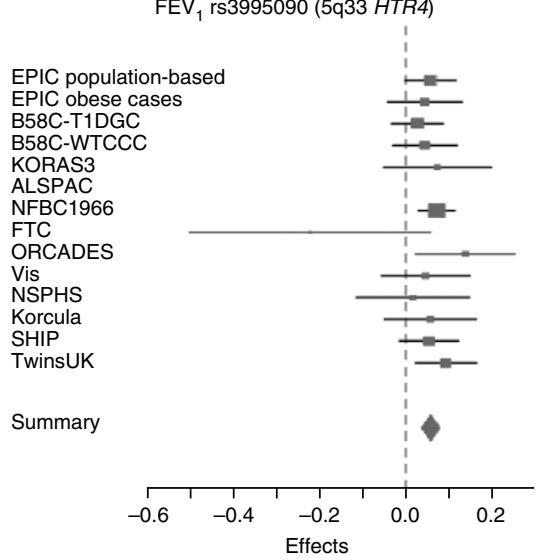

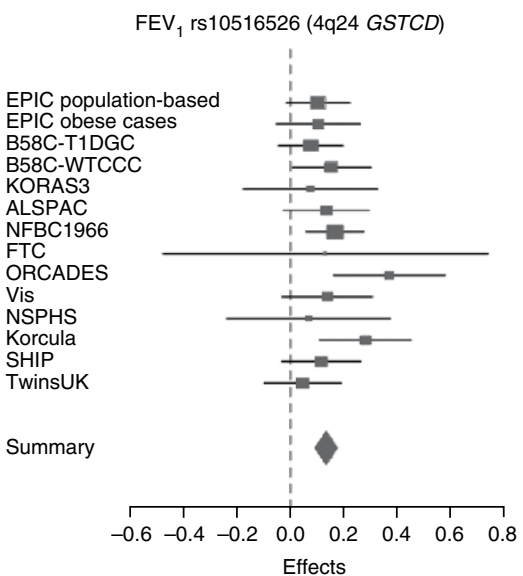

$\mathrm{FEV}_{1} / \mathrm{FVC}$ rs2070600 (6p21 AGER)

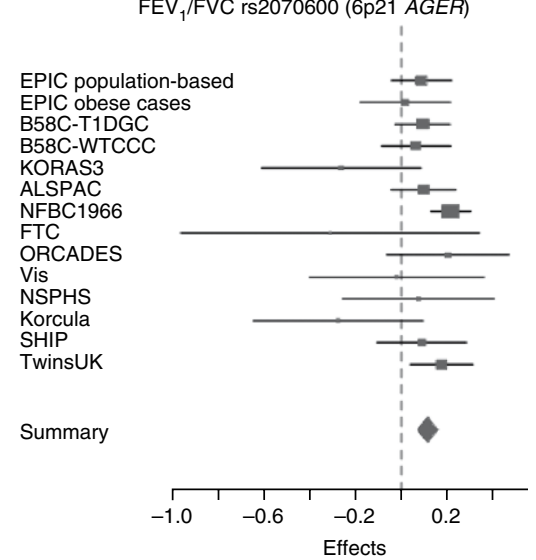

FEV $_{1} /$ FVC rs12504628 (4q31 HHIP)

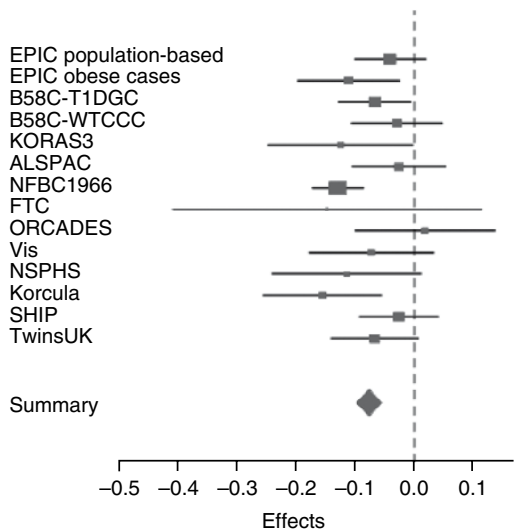

FEV $_{1} /$ FVC rs12899618 (15q23 THSD4)

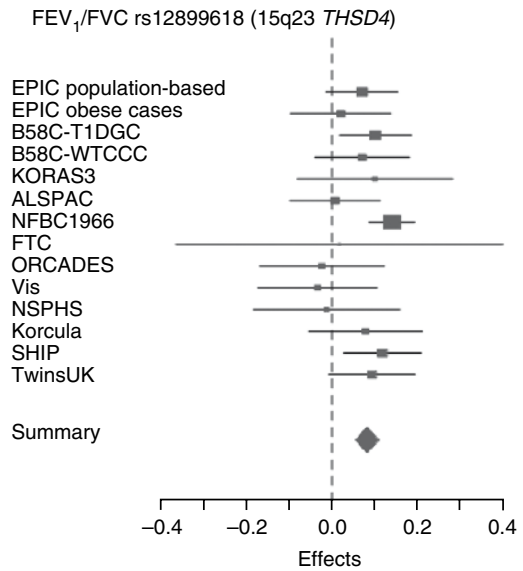

Figure 3 Forest plots of the stage 1 meta-analysis for the six lung function-associated loci. Each of the SNPs included in the figure showed genomewide significant association $\left(P<5 \times 10^{-8}\right)$ with either $\mathrm{FEV}_{1}$ or $\mathrm{FEV}_{1} / \mathrm{FVC}$ in the data from stages $1,2 \mathrm{a}$ and $2 \mathrm{~b}$. The plots show the meta-analysis of the stage 1 data for each sentinel SNP. The contributing effect (transformed beta) from each study is shown by a square, with confidence intervals indicated by horizontal lines. The contributing weight of each study to the meta-analysis is indicated by the size of the square. The combined meta-analysis estimate in the stage 1 data is shown at the bottom of each graph.

\section{Effect of smoking on SNP associations}

Adjustment for ever-smoking status in the stage 1 data (Table 3) did not show materially different effect-size estimates for the associations with the sentinel SNPs in TNS1, GSTCD, HTR4, AGER, THSD4 or HHIP. Similarly, adjustments for a quantitative measure of lifetime smoking exposure (pack-years) did not show substantially different effect-size estimates for the identified SNP associations (data not shown). We also tested the associations of the top SNPs in TNS1, GSTCD, HTR4, AGER and THSD4 separately in ever-smokers and never-smokers (Supplementary Table 4); all $P$ values were $>0.05$ for tests of interaction between smoking status and these SNPs on lung function.

\section{Gene expression}

We determined the mRNA expression profiles of GSTCD, HHIP, THSD4, TNS1, HTR4, AGER and NOTCH4 in human lung tissue and a series of primary cells. We detected all transcripts in lung tissue (Supplementary Fig. 2a) and bronchial epithelial cells (Supplementary Fig. 2b); six transcripts (excluding NOTCH4) were present in human airway smooth muscle cells. We also detected GSTCD, TNS1, HTR4, AGER and NOTCH4 transcripts in peripheral blood mononuclear cells (Supplementary Fig. 2b). For AGER, we noted the presence of two PCR products suggesting an unreported splice variant; we confirmed the presence of the splice variant by sequencing.

\section{DISCUSSION}

Our study reports a meta-analysis of GWAS results from 20,288 participants and follow-up analyses in 54,276 participants, identifying five novel genome-wide significant loci for pulmonary function. The regions identified were 4q24 (GSTCD), 2q35 (TNS1) and 5q33 (HTR4) for $\mathrm{FEV}_{1}$, and 6p21 (AGER) and 15q23 (THSD4) for $\mathrm{FEV}_{1} / \mathrm{FVC}$. In addition, we identified a region suggestive of association with $\mathrm{FEV}_{1} / \mathrm{FVC}$ at 6p21 in DAAM2. The companion manuscript from the CHARGE Consortium, which reports a GWAS of lung function in 20,890 participants, also identifies genome-wide significant associations at GSTCD, HTR4 and $A G E R^{30}$. Both SpiroMeta and CHARGE confirmed the previously reported association between $\mathrm{FEV}_{1}$ and $\mathrm{FEV}_{1} / \mathrm{FVC}$ and the $4 \mathrm{q} 31$ locus upstream of $H H I P^{11}$.

Our findings have several important implications. First, the loci identified were observed in the whole population studied and were not specific to smokers. The presence of genetic determinants of lung function that do not depend on prior smoking exposure has been suggested by previous studies of heritability ${ }^{8}$. This does not rule out a possible subset of genetic determinants with effects on lung function that are partially or wholly dependent on smoking exposure.

We have also attempted to address the issue of genetic factors that influence smoking behavior. We did not observe any association with the CHRNA3-CHRNA5-CHRNB4 locus previously reported to be associated with cigarette smoke exposure, lung cancer, peripheral arterial disease ${ }^{31}$ and $\mathrm{COPD}^{10}\left(\mathrm{rs} 1051730, P=0.23\right.$ for $\mathrm{FEV}_{1}$ and 0.56 
for $\mathrm{FEV}_{1}$ /FVC). The associations we show in GSTCD, TNS1, HTR4, THSD4 and AGER do not seem to be attenuated by adjustment for qualitative or quantitative adjustments for smoking exposure. None of these loci have been implicated in published GWAS of smoking quantity, although a recent report suggested a role for TSHD4 variants in smoking cessation ${ }^{32}$.

SNPs showing association with height could also show association with lung function measures because of incomplete adjustment for height, or because of SNP effects on skeletal growth with consequences for both height and lung function. The $4 \mathrm{q} 31$ locus near HHIP has shown convincing association with height ${ }^{33}$. An association was recently reported between height and rs185819 at $6 \mathrm{p} 21$ (ref. 34). Although this association signal was broad, reflecting the extended LD across this region of the MHC, rs 185819 was in weak LD $\left(r^{2}=0.069\right)$ with $r 22070600$ (the sentinel SNP we reported for $\mathrm{FEV}_{1} / \mathrm{FVC}$ in $A G E R$ ). These findings leave open the possibility of shared genetic determinants of growth of pulmonary function and height, but they do not suggest that our findings are primarily accounted for by inadequate adjustment for height.

The level of $\mathrm{FEV}_{1}$ at a given time point in an individual depends on two potentially independent processes: the maximum lung function obtained during development, and the rate of decline of lung function with age. Lung function reaches a maximum by age $25-35$ years $^{35}$. The populations studied in SpiroMeta cover a wide range of ages except the very elderly; as expected, $\mathrm{FEV}_{1}$ and $\mathrm{FVC}$ values were much lower in children. At least for the loci we identify, there was little evidence for age-specific effects, suggesting that the genetic risk factors identified operate across the age ranges; these findings again are in keeping with those of previous epidemiological studies ${ }^{7}$. Our analyses were based on cross-sectional measures of lung function; additional studies in cohorts with longitudinal data will be needed to identify determinants of the gradients of development and decline in lung function with age.

The magnitude of the estimated effect on untransformed $\mathrm{FEV}_{1}$ of rs 10516526 in GSTCD was $52 \mathrm{ml}$ per copy of the G allele (frequency, 0.06). This is equivalent to about 3 years of $\mathrm{FEV}_{1}$ decline in the nonsmoking population ${ }^{35}$. Allelic effect sizes on $\mathrm{FEV}_{1}$ of the more common variants (minor allele frequencies $\sim 0.4$ ) were $19-23 \mathrm{ml}$ for rs 3995090 in HTR4 and rs2571445 in TNS1. Individually, the five loci we describe account for a small proportion $(0.07 \%-0.14 \%)$ of the variance in $\mathrm{FEV}_{1}$ and in $\mathrm{FEV}_{1} / \mathrm{FVC}$ (Table 2) in the general population.

After exclusion of the locus near HHIP and the five reported regions, meta-analysis test statistics still showed an excess of extreme values compared with expected values under the null, particularly for $\mathrm{FEV}_{1}$. Although we cannot rule out the possibility of residual population stratification, this indicates the potential to detect further loci associated with lung function (Supplementary Fig. 1a,b). We have provided a list of the top 2000 associations for $\mathrm{FEV}_{1}$ and for $\mathrm{FEV}_{1} / \mathrm{FVC}$ (Supplementary Table 5) as a resource to other investigators.

We imputed nongenotyped SNPs using two software implementations $^{36,37}$ that share similar underlying population genetic models ${ }^{38}$. This methodology facilitates meta-analysis across different marker sets and improves coverage across the genome, and its utility has been empirically shown in several large GWAS. However, the power to detect associations with rare alleles is limited. The loci we report include two relatively infrequent SNPs, GSTCD (rs10516526, minor allele frequency 0.06) and AGER (rs2070600, minor allele frequency $0.05)$; these SNPs were directly genotyped in the majority of stage 1 subjects (16,514 and 15,386 individuals, respectively).

The associations we report relate to the general population but were of comparable magnitude after the exclusion of documented cases of asthma or COPD (data not shown). Although pulmonary function is an important predictor of morbidity and mortality per se, it will be important to investigate, in appropriately powered studies, whether the risk alleles in the genes identified in this study act as independent susceptibility markers for COPD or influence the development of airway obstruction in other diseases, such as asthma.

Our expression profiling studies identified expression of all of the candidate genes in relevant tissues. Further work is required to elucidate the mechanisms underlying the novel association signals we describe. In broad terms, however, it is notable that the most probable candidate genes in the regions identified seem to be involved either in developmental pathways important for lung growth or in tissue remodeling pathways that might be expected to alter airway architecture.

In conclusion, the results presented here from the SpiroMeta consortium, together with those reported by the CHARGE Consortium ${ }^{30}$, provide strong evidence for newly identified genetic loci that act as important determinants of pulmonary function.

\section{METHODS}

Methods and any associated references are available in the online version of the paper at http://www.nature.com/naturegenetics/.

Note: Supplementary information is available on the Nature Genetics website.

\section{ACKNOWLEDGMENTS}

We thank the many colleagues who contributed to collection and phenotypic characterization of the clinical sampling, genotyping and analysis of the GWAS data. We especially thank those who kindly agreed to participate in the studies.

Major funding for this work is from the following sources (in alphabetical order): Academy of Finland (including project grants 104781, 120315 and 1114194) and Center of Excellence in Complex Disease Genetics; Arthritis Research Campaign; Asthma UK; AstraZeneca; Biocenter Oulu, University of Oulu; Biocentrum Helsinki; Biotechnology and Biological Sciences Research Council project grant; British Heart Foundation (including project grants PG/06/154/22043 and PG/97012 and Senior Research Fellowship FS05/125); British Lung Foundation; Cancer Research United Kingdom; Chief Scientists Office, part of the Scottish Government Health Directorate (including grant CZD/16/6); Department of Health Air Pollution PRP (ref. no. 0020029); ENGAGE project (HEALTH-F4-2007-201413); European Commission (EURO-BLCS, FP-5/QLG1CT-2000-01643, FP-7/2007-2013, FP-6 LSHB-CT-2006-018996 (GABRIEL), FP-6 LSHG-CT-2006-01947 (EUROSPAN), HEALTH-F2-2008-201865-GEFOS and FP-5 GenomEUtwin project QLG2-CT-2002-01254); Finnish Ministry of Education; German Federal Ministry of Education and Research (BMBF, including grants 01ZZ96030, 01ZZ0701 and 01GI0883 and German Asthma and COPD Network (COSYCONET) grant 01GI0883); German Ministry for Education, Research and Cultural Affairs; German National Genome Research Network (NGFN-2 and NGFN-plus); Healthway, Western Australia; HEFCE Science Research Investment Fund; Helmholtz Zentrum München; German Research Center for Environmental Health, Neuherberg, Germany; International Osteoporosis Foundation; Juvenile Diabetes Research Foundation International; Leicester Biomedical Research Unit in Cardiovascular Science (NIHR); Medical Research Council UK (including grants G0500539, G0501942, G0000943 and G990146); Medical Research Fund of the Tampere University Hospital; Ministry for Social Affairs of the Federal State of Mecklenburg-West Pomerania; MRC Human Genetics Unit; Munich Center of Health Sciences, as part of LMUinnovativ; National Human Genome Research Institute; National Institute for Health Research comprehensive Biomedical Research Centre award to Guy's \& St. Thomas' NHS Foundation Trust in partnership with King's College London; National Institute for Health Research Cambridge Biomedical Research Centre; National Institute of Allergy and Infectious Diseases; National Institute of Child Health and Human Development; National Institute of Diabetes and Digestive and Kidney Diseases; National Heart, Lung, and Blood Institute (grant 5R01HL087679-02 through the STAMPEED program (1RL1MH083268-01)); Oulu University Hospital; PHOEBE (FP6, LSHG-CT-2006-518418); Public Population Project in Genomics (Genome Canada and Genome Quebec), Republic of Croatia Ministry of Science, Education and Sports (research grant 108-1080315-0302); Royal Society; Siemens Health Care Sector; Swedish Heart and Lung Foundation (grant 20050561); Swedish Medical Research Council (project no. K2007-66X-20270-01-3); Swedish Research Council 
for Working Life and Social Research (FAS, grants 2001-0263 and 2003-0139); the Great Wine Estates of the Margaret River region of Western Australia; UBS Wealth Foundation (grant BA29s8Q7-DZZ); UK Department of Health Policy Research Programme; University of Nottingham; University of Bristol; US National Institutes of Health (U01 DK062418); US National Institutes of Health-National Institute of Mental Health (5R01MH63706:02); Wellcome Trust (including grants 068545/Z/02, 076113/B/04/Z, 079895, 077016/Z/05/Z, 075883 and 086160/Z/08/A); and Zentren für Innovationskompetenz (BMBF grant 03ZIK012).

\section{AUTHOR CONTRIBUTIONS}

Author contributions are listed in alphabetical order. See Table 1 for definitions of study acronyms.

Project conception, design and management. Stage 1 GWAS, ALSPAC: J. Henderson, R.G. B58C: D.P.S. EPIC: I.B., R.J.F.L., N.J.W., J.H.Z. FTC: J.K., T.R. KORA S3: H.E.W. Korcula: H.C., I.G., S.J., I.R., A.F.W., L.Z. NFBC1966: P.E., M.-R.J., A.P., L.P. NSPHS: U.G. ORCADES: H.C., S.H.W., J.F.W., A.F.W. SHIP: S.G., G.H., B.K., H.V. TwinsUK: T.D.S., G. Zhai. Vis: H.C., C.H., O.P., I.R., A.F.W. Stage $2 a$ follow-up, ADONIX: A.-C.O., K.T. BHS: A.L.J., L.J.P. GS:SFHS: H.C., C.J., A.D.M., D.J.P. HCS: C.C., E.D., J.W.H. KORA F4: S.K, E.S., H.S. NFBC1986: A.-L.H., M.-R.J. Nottingham Smokers: I.P.H., I. Sayers, M.O. NSHD: The NSHD Respiratory Study Team. Stage $2 b$ in silico follow-up, Health 2000: M.H., M.K., L.P. Phenotype collection and data management. Stage 1 GWAS, ALSPAC: J. Henderson, R.G. B58C: D.P.S., A.R.R. EPIC: N.J.W. FTC: J.K., L.M., T.R. KORA S3: H.E.W. Korcula: I.G., S.J., O.P., I.R., L.Z. NFBC1966: P.E., M.-R.J., A.-L.H., A.P. NSPHS: G. Zaboli. ORCADES: H.C., S.H.W., J.F.W. SHIP: S.G., B.K., H.V. TwinsUK: M.M., T.D.S. Vis: H.C., C.H., O.P., I.R., A.F.W. Stage 2 a follow-up, ADONIX: A.-C.O., K.T. BHS: M.N.C., A.L.J., L.J.P. BRHS: R.W.M., S.G.W., P.H.W. BWHHS: G.D.S., S.E., D.A.L., P.H.W. Gedling: J.R.B., T.M.M., I.D.P. GS:SFHS: C.J., D.J.P. HCS: C.C., E.D., S.S. KORA F4: S.K., E.S., H.S. NFBC1986: A.-L.H., M.-R.J. Nottingham Smokers: J.D.B., I.P.H., I. Sayers, M.O. NSHD: The NSHD Respiratory Study Team. Stage $2 b$ in silico follow-up, Health 2000: M.H., M.K.

Genotyping. Stage 1 GWAS, ALSPAC: P.D. B58C: W.L.M., WTCCC. EPIC: I.B., R.J.F.L., N.J.W., J.H.Z. FTC: J.K., I. Surakka. KORA S3: M.I., N.M.P.-H., H.G. NFBC1966: P.E., M.-R.J., L.P. ORCADES: H.C., J.F.W. SHIP: G.H. TwinsUK: N.S. Vis: C.H., I.R., A.F.W. Stage $2 a$ follow-up, ADONIX: A.T.N., F.N. BRHS: A.D.H., R.W.M., P.H.W. GS:SFHS: A.D.M. HCS: C.C., E.D., J.W.H. KORA F4: H.G. NFBC1986: N.B.-N., J.D., P.F., M.-R.J., L.P. Nottingham Smokers: I.P.H. NSHD: D.K., A.W. STAGE $2 b$ in silico follow-up, Health 2000: L.P., S.R., I. Surakka. Data analysis. Stage 1 GWAS, ALSPAC: D.M.E. B58C: A.R.R. EPIC: R.J.F.L., J.H.Z. FTC: I. Surakka., L.M. KORA S3: E.A., M.I., N.M.P.-H. Korcula: C.H., J.E.H., V.V. NFBC1966: A.R. NSPHS: W.I., A.J. ORCADES: C.H., V.V. SHIP: S.G., G.H., B.K, H.V. TwinsUK: G. Zhai. Vis: C.H., V.V. Stage 2 a follow-up, ADONIX: A.T.N., F.N., A.-C.O, K.T. BHS: M.N.C., J. Hui., L.J.P. BRHS: R.W.M. BWHHS: D.A.L. Gedling: M.O., M.D.T. GS:SFHS: A.K.M. HCS: J.W.H., S.S. KORA F4: E.A, H.G. NFBC1986: A.R. Nottingham Smokers: M.O., I. Sayers, M.D.T. NSHD: The NSHD Respiratory Study Team. Stage $2 b$ in silico follow-up, Health 2000: M.K., S.R., I. Surakka.

Meta-analysis group. P.R.B., I.P.H., T.J., E.R., D.P.S., M.D.T., L.V.W. Bioinformatics and expression profiling groups. I.P.H., M.O., I. Sayers, E.R., M.D.T., L.V.W.

Writing group. P.E., I.P.H., E.R., I. Sayers, D.P.S., M.D.T., L.V.W.

\section{COMPETING INTERESTS STATEMENT}

The authors declare competing financial interests: details accompany the full-text HTML version of the paper at http://www.nature.com/naturegenetics/.

Published online at http://www.nature.com/naturegenetics/.

Reprints and permissions information is available online at http://npg.nature.com/ reprintsandpermissions/.

1. Myint, P.K. et al. Respiratory function and self-reported functional health: EPICNorfolk population study. Eur. Respir. J. 26, 494-502 (2005).

2. Schünemann, H.J., Dorn, J., Grant, B.J., Winkelstein, W. Jr. \& Trevisan, M. Pulmonary function is a long-term predictor of mortality in the general population: 29-year follow-up of the Buffalo Health Study. Chest 118, 656-664 (2000).

3. Strachan, D.P. Ventilatory function, height, and mortality among lifelong nonsmokers. J. Epidemiol. Community Health 46, 66-70 (1992).

4. Young, R.P., Hopkins, R. \& Eaton, T.E. Forced expiratory volume in one second: not just a lung function test but a marker of premature death from all causes. Eur. Respir. J. 30, 616-622 (2007).

5. Hubert, H.B., Fabsitz, R.R., Feinleib, M. \& Gwinn, C. Genetic and environmental influences on pulmonary function in adult twins. Am. Rev. Respir. Dis. 125, 409-415 (1982).
6. McClearn, G.E., Svartengren, M., Pedersen, N.L., Heller, D.A. \& Plomin, R. Genetic and environmental influences on pulmonary function in aging Swedish twins. J. Gerontol. 49, 264-268 (1994).

7. Lewitter, F.I., Tager, I.B., McGue, M., Tishler, P.V. \& Speizer, F.E. Genetic and environmental determinants of level of pulmonary function. Am. J. Epidemiol. 120, 518-530 (1984).

8. Palmer, L.J. et al. Familial aggregation and heritability of adult lung function: results from the Busselton Health Study. Eur. Respir. J. 17, 696-702 (2001).

9. Loos, R.J. et al. Common variants near MC4R are associated with fat mass, weight and risk of obesity. Nat. Genet. 40, 768-775 (2008).

10. Pillai, S.G. et al. A genome-wide association study in chronic obstructive pulmonary disease (COPD): identification of two major susceptibility loci. PLoS Genet. 5, e1000421 (2009).

11. Wilk, J.B. et al. A genome-wide association study of pulmonary function measures in the Framingham Heart Study. PLoS Genet. 5, e1000429 (2009).

12. McCarthy, M.I. et al. Genome-wide association studies for complex traits: consensus, uncertainty and challenges. Nat. Rev. Genet. 9, 356-369 (2008).

13. Miller, L.-A.D. et al. Role of Sonic hedgehog in patterning of tracheal-bronchial cartilage and the peripheral lung. Dev. Dyn. 231, 57-71 (2004).

14. Hayes, J.D., Flanagan, J.U. \& Jowsey, I.R. Glutathione transferases. Annu. Rev Pharmacol. Toxicol. 45, 51-88 (2005).

15. Baillat, D. et al. Integrator, a multiprotein mediator of small nuclear RNA processing, associates with the C-terminal repeat of RNA polymerase II. Cell 123, 265-276 (2005).

16. Weigt, C., Gaertner, A., Wegner, A., Korte, H. \& Meyer, H.E. Occurrence of an actin-inserting domain in tensin. J. Mol. Biol. 227, 593-595 (1992).

17. Chen, H., Duncan, I.C., Bozorgchami, H. \& Lo, S.H. Tensin 1 and a previously undocumented family member, tensin2, positively regulate cell migration. Proc. Natl. Acad. Sci. USA 99, 733-738 (2002).

18. Manzke, T. et al. 5-HT4(a) receptors avert opioid-induced breathing depression without loss of analgesia. Science 301, 226-229 (2003).

19. Dupont, L.J. et al. The effects of $5-\mathrm{HT}$ on cholinergic contraction in human airways in vitro. Eur. Respir. J. 14, 642-649 (1999).

20. Bayer, H. et al. Serotoninergic receptors on human airway epithelial cells. Am. J. Respir. Cell Mol. Biol. 36, 85-93 (2007).

21. Mägert, H.J. et al. LEKTI, a novel 15-domain type of human serine proteinase inhibitor. J. Biol. Chem. 274, 21499-21502 (1999).

22. Kipreos, E.T. \& Pagano, M. The F-box protein family. Genome Biol. 1, REVIEWS3002 (2000).

23. Sparvero, L.J. et al. RAGE (Receptor for Advanced Glycation Endproducts), RAGE ligands, and their role in cancer and inflammation. J. Transl. Med. 7, 17 (2009).

24. Fehrenbach, H. et al. Receptor for advanced glycation endproducts (RAGE) exhibits highly differential cellular and subcellular localisation in rat and human lung. Cell. Mol. Biol. 44, 1147-1157 (1998).

25. Konishi, K. et al. Gene expression profiles of acute exacerbations of Idiopathic Pulmonary Fibrosis. Am. J. Respir. Crit. Care Med. 180, 167-175 (2009).

26. Englert, J.M. et al. A role for the receptor for advanced glycation end products in idiopathic pulmonary fibrosis. Am. J. Pathol. 172, 583-591 (2008).

27. Fortini, M.E. Notch signaling: the core pathway and its posttranslational regulation. Dev. Cell 16, 633-647 (2009).

28. Favre, C.J. et al. Expression of genes involved in vascular development and angiogenesis in endothelial cells of adult lung. Am. J. Physiol. Heart Circ. Physiol. 285, H1917-H1938 (2003).

29. Chen, H., Herndon, M.E. \& Lawler, J. The cell biology of thrombospondin-1. Matrix Biol. 19, 597-614 (2000).

30. Hancock, D.B. et al. Meta-analyses of genome-wide association studies identify multiple loci associated with pulmonary function. Nat. Genet. advance online publication, doi:10.1038/ng.500 (13 December 2009).

31. Thorgeirsson, T.E. et al. A variant associated with nicotine dependence, lung cancer and peripheral arterial disease. Nature 452, 638-642 (2008).

32. Uhl, G.R. et al. Molecular genetics of successful smoking cessation: convergent genome-wide association study results. Arch. Gen. Psychiatry 65, 683-693 (2008).

33. Weedon, M.N. et al. Genome-wide association analysis identifies 20 loci that influence adult height. Nat. Genet. 40, 575-583 (2008).

34. Gudbjartsson, D.F. et al. Many sequence variants affecting diversity of adult human height. Nat. Genet. 40, 609-615 (2008).

35. Kohansal, R. et al. The natural history of chronic airflow obstruction revisited: an analysis of the framingham offspring cohort. Am. J. Respir. Crit. Care Med. 180, 3-10 (2009).

36. Li, Y. \& Abecasis, G.R. Mach 1.0: Rapid haplotype reconstruction and missing genotype inference. Am. J. Hum. Genet. S79, 2290 (2006)

37. Marchini, J., Howie, B., Myers, S., McVean, G. \& Donnelly, P. A new multipoin method for genome-wide association studies by imputation of genotypes. Nat. Genet. 39, 906-913 (2007).

38. Guan, Y. \& Stephens, M. Practical issues in imputation-based association mapping. PLoS Genet. 4, e1000279 (2008).

39. Myers, S., Bottolo, L., Freeman, C., McVean, G. \& Donnelly, P. A fine-scale map of recombination rates and hotspots across the human genome. Science $\mathbf{3 1 0}$ 321-324 (2005). 
${ }^{1}$ Departments of Health Sciences and Genetics, Adrian Building, University of Leicester, Leicester, UK. ${ }^{2}$ Division of Therapeutics and Molecular Medicine, Nottingham Respiratory Biomedical Research Unit, University Hospital of Nottingham, Nottingham, UK. ${ }^{3}$ Clinical Pharmacology, William Harvey Research Institute, Barts and The London School of Medicine and Dentistry, Queen Mary, University of London, London, UK. ${ }^{4}$ Medical Research Council (MRC) Epidemiology Unit, Institute of Metabolic Science, Cambridge, UK. ${ }^{5}$ Respiratory Epidemiology and Public Health Group, National Heart and Lung Institute, Imperial College London, London, UK. ${ }^{6}$ Department of Epidemiology and Public Health, Imperial College London, St. Mary's Campus, London, UK. ${ }^{7}$ Department of Twin Research and Genetic Epidemiology, King's College London, London, UK. ${ }^{8}$ MRC Human Genetics Unit, Institute of Genetics and Molecular Medicine, Western General Hospital, Edinburgh, Scotland, UK. ${ }^{9}$ Department of Genetics and Pathology, Rudbeck Laboratory, Uppsala University, Uppsala, Sweden. ${ }^{10}$ Institute of Epidemiology, Helmholtz Zentrum München, German Research Center for Environmental Health, Neuherberg, Germany. ${ }^{11}$ Wellcome Trust Sanger Institute, Cambridge, UK. ${ }^{12}$ Department of CommunityBased Medicine, ${ }^{13}$ Department of Social Medicine and ${ }^{14}$ Avon Longitudinal Study of Parents and Children (ALSPAC) Laboratory, Department of Social Medicine, University of Bristol, Bristol, UK. ${ }^{15}$ Division of Community Health Sciences, St. George's University of London, London, UK. ${ }^{16}$ A full list of members is provided in the Supplementary Note. ${ }^{17}$ Department of Public Health, University of Helsinki, Helsinki, Finland. ${ }^{18}$ Department of Health Sciences and Finnish Center for Interdisciplinary Gerontology, University of Jyväskylä, Jyväskylä, Finland. ${ }^{19}$ Institute for Molecular Medicine Finland FIMM, University of Helsinki, Helsinki, Finland. ${ }^{20}$ National Institute for Health and Welfare, Helsinki, Finland. ${ }^{21}$ Department of Chronic Disease Epidemiology/NICER, Institute of Social and Preventive Medicine, University of Zürich, Zürich, Switzerland. ${ }^{22}$ Institute of Medical Informatics, Biometry and Epidemiology, Ludwig-Maximilians-Universität, Munich, Germany. ${ }^{23}$ Klinikum Grosshadern, Munich, Germany. ${ }^{24}$ Croatian Centre for Global Health, The University of Split Medical School, Split, Croatia. ${ }^{25}$ Andrija Stampar School of Public Health, Faculty of Medicine, University of Zagreb, Zagreb, Croatia. ${ }^{26}$ Department of Clinical Sciences, Obstetrics and Gynecology, Institute of Clinical Medicine, University of Oulu, Oulu, Finland. ${ }^{27}$ Centre for Population Health Sciences, University of Edinburgh, Edinburgh, Scotland, UK. ${ }^{28}$ Department of Internal Medicine B-Cardiology, Intensive Care, Pulmonary Medicine and Infectious Diseases, ${ }^{29}$ Interfaculty Institute for Genetics and Functional Genomics and ${ }^{30}$ Institute for Community Medicine, SHIP/Clinical-Epidemiological Research, University of Greifswald, Greifswald, Germany. ${ }^{31}$ Gen-Info, Zagreb, Croatia. ${ }^{32}$ Department of Lifecourse and Services, National Institute for Health and Welfare, Oulu, Finland. ${ }^{33}$ Department of Microbiology and Immunology, Institute of Biomedicine. ${ }^{34}$ Occupational and Environmental Medicine, Sahlgrenska Academy, University of Gothenburg, Gothenburg, Sweden. ${ }^{35} \mathrm{Centre}$ for Genetic Epidemiology and Biostatistics, University of Western Australia, Perth, Western Australia, Australia. ${ }^{36}$ Department of Pulmonary Physiology/West Australian Sleep Disorders Research Institute and ${ }^{37}$ Busselton Population Medical Research Foundation, Sir Charles Gairdner Hospital, Western Australia, Australia. ${ }^{38}$ Department of Epidemiology and Public Health and ${ }^{39}$ Department of Primary Care and Population Health, University College London, London, UK. ${ }^{40}$ MRC Centre for Causal Analyses in Translational Epidemiology, Department of Social Medicine, University of Bristol, Bristol, UK. ${ }^{41}$ Non-Communicable Diseases Epidemiology Unit, Department of Epidemiology and Population Health, London School of Hygiene and Tropical Medicine, London, UK. 42Division of Epidemiology and Public Health, School of Community Health Sciences and ${ }^{43}$ Nottingham Respiratory Biomedical Research Unit, University of Nottingham, Nottingham, UK. ${ }^{44}$ Institute for Lung Health, Glenfield Hospital, University Hospitals of Leicester National Health Service Trust, Leicester, UK. ${ }^{45}$ Medical Genetics Section, Centre for Molecular Medicine, Institute of Genetics and Molecular Medicine, University of Edinburgh, Western General Hospital, Edinburgh, UK. ${ }^{46}$ Biomedical Research Institute, Ninewells Hospital, University of Dundee, Dundee, UK. ${ }^{47}$ MRC Epidemiology Resource Centre, University of Southampton, Southampton General Hospital, Southampton, UK. ${ }^{48}$ National Institute for Health Research (NIHR) Musculoskeletal Biomedical Research Unit, University of Oxford, Oxford, UK. ${ }^{49}$ Institute of Lung Biology and Disease, Helmholtz Zentrum München, German Research Center for Environmental Health, Neuherberg, Germany. ${ }^{50}$ CNRS $8090-$ Institute of Biology, Pasteur Institute, Lille, France. ${ }^{51}$ Section of Genomic Medicine, Imperial College London, Hammersmith Hospital, London, UK. ${ }^{52}$ A full list of members is provided in the Supplementary Note. ${ }^{53}$ MRC National Survey of Health and Development, MRC Unit for Lifelong Health and Ageing, London, UK. ${ }^{54}$ Human Genetics Division and ${ }^{55}$ Infection, Inflammation and Immunity Division, School of Medicine, University of Southampton, Southampton General Hospital, Southampton, UK. ${ }^{6}$ Molecular Genetics, PathWest Laboratory Medicine WA, Nedlands, Western Australia, Australia. ${ }^{57}$ AstraZeneca Research and Development, Mölndal, Sweden. ${ }^{58}$ Institute of Health Sciences, University of Oulu, Oulu, Finland. ${ }^{59}$ Biocenter Oulu, University of Oulu, Oulu, Finland. ${ }^{60}$ Bute Medical School, University of St. Andrews, St. Andrews, Fife, UK. ${ }^{61}$ Department of Clinical Physiology, University of Tampere and Tampere University Hospital, Tampere, Finland. ${ }^{62}$ Institute of Social and Preventive Medicine at Swiss Tropical Institute, University of Basel, Basel, Switzerland. ${ }^{63} \mathrm{MRC}-$ Health Protection Agency (HPA) Centre for Environment and Health, Imperial College London, London, UK.

${ }^{64}$ These authors contributed equally to this work. Correspondence should be addressed to M.D.T. (mt47@leicester.ac.uk) or I.P.H. (ian.hall@nottingham.ac.uk). 


\section{ONLINE METHODS}

Study design. The study consisted of two stages. In stage 1, a meta-analysis was conducted on directly genotyped and imputed SNPs from 14 studies of individuals of European ancestry, with a total sample size of 20,288. Details of these studies are given in Table 1. This meta-analysis provided loci for further genotyping in up to 32,184 individuals of European origin (stage 2a) and in silico comparisons in 22,092 individuals of European origin (stage 2b).

Stage 1 samples. The SpiroMeta consortium consists of 14 GWAS studies: ALSPAC, B58C-T1DGC, B58C-WTCCC, EPIC (obese and population-based substudies), the EUROSPAN studies (Korcula, NSPHS, ORCADES and Vis), FTC (incorporating the FinnTwin 16 and Finnish Twin Study on Aging), KORA S3, NFBC1966, SHIP and TwinsUK (see Table 1 for definitions of acronyms). The primary analyses on $\mathrm{FEV}_{1}$ and $\mathrm{FEV}_{1} / \mathrm{FVC}$ included 20,288 individuals of European descent. The measurements of $\mathrm{FEV}_{1}$ and $\mathrm{FVC}$ are described in the Supplementary Note.

Genome-wide genotyping and quality control. The platforms used were Affymetrix 500K GeneChip array (four studies), Illumina HumanHap 550 Beadchip (one study), Illumina 317K (four studies), Affymetrix Genome-Wide SNP6.0 (one study), Illumina Hap370cnv (one study), Illumina Hap300 v1 (one study) and Illumina Hap300 v2 (two studies). Each individual study applied quality-control criteria as described in Supplementary Table 1.

Imputation. Imputation of nongenotyped SNPs was undertaken with $\mathrm{MACH}^{36}$ or IMPUTE ${ }^{37}$ with preimputation filters and parameters as shown in Supplementary Table 1. SNPs were excluded if the imputation information, assessed using $r$ 2.hat (MACH) or .info (IMPUTE), was $<0$. . In total, 2,705,257 autosomal SNPs were analyzed.

Transformation of data and genotype-phenotype association analysis. Linear regression of age, age ${ }^{2}$, sex, height and ancestry principal components was undertaken on $\mathrm{FEV}_{1}$ (milliliters) and $\mathrm{FEV}_{1} / \mathrm{FVC}$ (percentage). The residuals were transformed to ranks and subsequently to normally distributed $z$ scores, and were then used as the phenotype for association testing under an additive genetic model using software specified in Supplementary Table 1. Appropriate tests for association in related individuals were applied where necessary, as described in the Supplementary Note.

Meta-analysis of stage 1 data. All stage 1 study effect estimates were corrected using genomic control ${ }^{40}$ and were oriented to the forward strand of the NCBI build 36 reference sequence of the human genome, consistently using the alphabetically higher allele as the coded allele. Study-specific lambda estimates are shown in Supplementary Table 1. The pooled effect-size estimate and s.e.m. were computed using inverse variance weighting, and genomic control was applied to the pooled effect-size estimates. To describe the effect of imperfect imputation on power, we report ' $N$ effective', the sum of the study-specific products of the sample size and the imputation quality metric. Meta-analysis statistics and figures were produced using $\mathrm{R}$ version 2.7.0.

Selection of SNPs for stage 2. Ten leading SNPs were selected for stage 2a genotyping follow-up (Supplementary Table 2). Thirty leading SNPs were selected for stage $2 \mathrm{~b}$ in silico exchange, according to $P$ value (under the threshold of $5 \times 10^{-5}$ ), $N$ effective ( $\geq 70 \%$ of the total sample size) and evidence from supporting SNPs (Supplementary Table 3 ).

Stage 2a samples (follow-up genotyped data). We genotyped 10 SNPs in up to 32,184 individuals from the ADONIX, BHS, BRHS, BWHHS, Gedling,
GS:SFHS, HCS, KORA F4, NFBC1986, Nottingham Smokers and NSHD studies. The characteristics of the studies are summarized in Table 1, and stage 2a study information is provided in the Supplementary Note.

Stage 2b samples (in silico data). The CHARGE Consortium includes four population-based studies with data on $\mathrm{FEV}_{1}$ and $\mathrm{FEV}_{1} / \mathrm{FVC}$ : the Atherosclerosis Risk in Communities (ARIC) study, the Cardiovascular Health Study (CHS), the Framingham Heart Study (FHS) and the Rotterdam Study (RS). Details are provided in the companion paper in this issue from the CHARGE Consortium $^{30}$. Given differences between the analysis approaches for GWAS adopted by the SpiroMeta and CHARGE consortia, the CHARGE analyses were undertaken using the analysis approach adopted by the SpiroMeta consortium (21,209 individuals; larger than the sample in the companion paper, which excluded subjects with missing or incomplete pack-years data). We also included 883 population-based subjects from the Health 2000 study in the stage $2 \mathrm{~b}$ analysis.

Combined analysis of stage 1 and 2 samples. Meta-analysis of data from stages $1,2 \mathrm{a}$ and $2 \mathrm{~b}$ was conducted using inverse variance weighting. We described associations as genome-wide significant if $P<5 \times 10^{-8}$.

Secondary analyses. To examine the effect of smoking on the causal pathway between the SNPs and the traits of interest, an adjustment for smoking was applied. The subgroups of 'ever-smokers' and 'never-smokers' were analyzed separately, and the stratum-specific estimated effects were combined within each individual study using inverse variance weights before meta-analyzing over studies. Additional adjustments were undertaken by adjusting for pack-years among the ever-smokers with these data available, and repeating the analyses.

PCR expression profiling. The mRNA expression profiles of GSTCD, HHIP, THSD4, TNS1, HTR4, AGER and NOTCH4 were determined in human lung tissue and primary cell samples using RT-PCR, including RNA from lung (Ambion/ABI), brain, airway smooth muscle cells ${ }^{41}$ and human bronchial epithelial cells $\left(\right.$ Clonetics $\left.^{42}\right)$. Peripheral blood mononuclear cells were isolated from whole blood using $6 \%(\mathrm{w} / \mathrm{v})$ dextran and $42 \%-51 \%(\mathrm{v} / \mathrm{v})$ Percoll gradients (Sigma). Ethical approval for the use of primary cells was obtained from the local ethics committees. Total RNA was extracted from samples using an RNeasy kit (Qiagen) as directed by the manufacturer. cDNA was generated from $1 \mu \mathrm{g}$ of RNA template using random hexamers and a SuperScript kit (Invitrogen) as directed by the manufacturer. PCR assays were designed to cross intron-exon boundaries and where splice variation was known, in order to detect all variants. Primer sequences are given in Supplementary Table 6. All PCR was done using Platinum Taq High Fidelity (Invitrogen) with $100 \mathrm{ng}$ of cDNA template in a $25-\mu \mathrm{l}$ reaction. Cycling conditions were as follows: $94^{\circ} \mathrm{C}$ for $3 \mathrm{~min}, 35$ cycles of $94^{\circ} \mathrm{C}$ for $45 \mathrm{~s}, 55^{\circ} \mathrm{C}$ for $30 \mathrm{~s}$, and $72{ }^{\circ} \mathrm{C}$ for $90 \mathrm{~s}$.

URLs. UCSC browser, http://genome.ucsc.edu/.

40. Devlin, B. \& Roeder, K. Genomic control for association studies. Biometrics 55, 997-1004 (1999)

41. Sayers, I., Swan, C. \& Hall, I.P. The effect of beta2-adrenoceptor agonists on phospholipase $\mathrm{C}$ (beta1) signalling in human airway smooth muscle cells. Eur. J. Pharmacol. 531, 9-12 (2006).

42. Wadsworth, S.J., Nijmeh, H.S. \& Hall, I.P. Glucocorticoids increase repair potential in a novel in vitro human airway epithelial wounding model. J. Clin. Immunol. 26, 376-387 (2006). 